\title{
Brincando de samba: as "rodas" fora da Política Patrimonial
}

\section{Marcus Bernardes \\ Universidade Federal do Recôncavo da Bahia}

Resumo: Neste artigo apresento de forma geral o processo de patrimonialização do Samba de Roda do Recôncavo Baiano. A partir dos grupos da cidade de Conceição do Jacuípe, pertencentes à Associação de Sambadores e Sambadeiras do Estado da Bahia (ASSEBA), sinalizo as tradições dos sambas existentes justapostas à dimensão da Política Patrimonial. As "rodas" fora dessa política são enfatizadas através de uma etnografia dos Sambas no/do Sertão baiano, na cidade de Riachão do Jacuípe, foco central deste trabalho.

Palavras-Chave: Patrimônio Cultural; Cultura Popular; Etnografia; Sambas de Roda. 


\title{
Playing samba: the "wheels" outside the Heritage Policy
}

\begin{abstract}
In this article I present in a general way the heritage process of the Samba de Roda do Recôncavo Baiano. From the groups of the city of Conceição do Jacuípe, belonging to the Associação de Sambadores e Sambadeiras do Estado da Bahia (ASSEBA), I signal the traditions of existing sambas juxtaposed to the dimension of the Heritage Policy. The "wheels" outside this policy are emphasized through an ethnography about Sambas in/of Sertão baiano, in the city of Riachão do Jacuípe, central focus oh this paperwork.
\end{abstract}

Keywords: Cultural Heritage; Popular Culture; Ethnography; Sambas de Roda.

\section{Jugando de samba: las "ruedas" fuera de la Política Patrimonial}

Resumen: En este artículo se presenta de manera general el processo de patrimonialización del Samba de Roda do Recôncavo Baiano. Desde de los grupos de la ciudad de Conceição do Jacuípe, pertenecientes a la Associação de Sambadores e Sambadeiras do Estado da Bahia (ASSEBA), señalo las tradiciones de sambas existentes yuxtapuestos a dimensión de la Política Patrimonial. Las "ruedas" fora de esa política se enfatizan mediante una etnografía de Sambas en/de Sertão baiano, en la ciudad de Riachão do Jacuípe, foco central de este trabajo.

Palabras Clave: Patrimonio Cultural; Cultura Popular; Etnografia; Sambas de Roda. 


\section{Afinando a escrita}

Escrever sobre algo tão sensorial, posto na dimensão do sensível, como a música, parece desde o início uma empreitada fadada à incompletude. Há sempre limites na escrita e por sorte, cabe à imaginação do leitor preencher as lacunas aonde a descrição não chega. Contudo, as musicalidades aqui representadas, embora sejam elementos chaves e a base sobre as indagações que se seguem, muitas vezes dividirão o solo com outras vozes mais pragmáticas. Fazendo coro às vozes, toques, gestos de sambadores e sambadeiras de duas pequenas cidades do interior baiano, há também uma harmonia complexa que envolve o Estado e políticas públicas, muitas vezes compondo acordes dissonantes.

Neste artigo apresento de forma geral o processo de patrimonialização do Samba de Roda do Recôncavo Baiano. Este processo ocorreu por volta dos anos de 2004 e 2005. A partir dos grupos da cidade de Conceição do Jacuípe, pertencentes à ASSEBA1, sinalizo as tradições dos sambas existentes justapostas à dimensão da Política Patrimonial. As práticas desta associação informam diretamente sobre as relações entre o Estado e os grupos. As "rodas" fora desta política são enfatizadas através dos Sambas no/do Sertão baiano, na cidade de Riachão do Jacuípe, foco central deste trabalho. Por fim, abordo algumas formas nas quais os sujeitos são interpelados pela Política Patrimonial, buscando inserir diferentes perspectivas envolvidas numa política pública tão ampla. Entendo que a permanência de múltiplos referenciais para sambadores e sambadeiras é também indicativo de resistência aos discursos uniformizantes desta política.

A antropologia não se define por nenhum objeto concreto, mas pelo seu olhar sobre a questão da diferença (CARDOSO DE OLIVEIRA, 2006). O diálogo proposto na etnografia sobre uma musicalidade, além da dimensão "compreensiva" da antropologia, deve almejar um entendimento também através da música. Dessa forma, o conhecimento construído e aqui representado em escrita é baseado nas vivências musicais, nos rituais, vozes, sons, gestos e ensinamentos dos mestres e mestras dos Sambas de Roda na Bahia. As categorias utilizadas para compreender os sambas de rodas são referendadas a partir do contexto prático dos sambas e das falas de seus mestres e mestras.

Os Sambas de Roda envolvem toda uma poética de sons e versos. Toda uma coreografia, dança e uso do corpo. O corpo que dança, o corpo que toca, o corpo que canta, o corpo que também é instrumento. A roda é ordem, é aprendizagem, é uma pedagogia. Os sambas também são brincadeiras, criam redes de solidariedade, fazem parte do trabalho no campo ou festividades citadinas. Embora sambas que envolvam a presença da roda estejam presentes

1 Associação de Sambadores e Sambadeiras do Estado da Bahia. 
em diversos estados brasileiros2, os Sambas de Roda aqui representados se referem aos grupos que fazem parte da ASSEBA, que abarca principalmente grupos da região do Recôncavo baiano, Salvador e regiões metropolitanas, Feira de Santana e Irará; e que são oficialmente considerados Patrimônio Cultural Brasileiro. E grupos do Sertão baiano, que são Sambas de Roda fora da Política Patrimonial.

\section{O Processo de Patrimonialização do Samba de Roda do Recôncavo Baiano}

Carlos Sandroni, em 2004, foi coordenador da candidatura do Samba de Roda do Recôncavo Baiano à III Proclamação de Obras-Primas do Patrimônio Imaterial da Humanidade, organizado pela UNESCO3. O Samba de Roda foi registrado como Patrimônio Imaterial Brasileiro em setembro de 2004; no mês seguinte foi enviado um dossiê em conjunto com um Plano de Ações4 exigidos pela UNESCO para o processo de candidatura. A inclusão de um bem em um dos livros de Registro é feita através de uma proposta formal de instituições públicas ou privadas, acompanhadas de documentos que descrevam a "relevância" do bem. A proposta de Registro do Samba de Roda foi encaminhada ao IPHAN5 pela Associação Cultural do Samba de Roda Dalva Damiana, Grupo Cultural Filhos de Nagô e pela Associação de Pesquisa em Cultura Popular e Música Tradicional do Recôncavo. Para o Registro do Samba de Roda foi utilizado o mesmo dossiê enviado à UNESCO (SANDRONI, 2010). Em abril de 20056 foi criada a ASSEBA, como um novo mecanismo de representação para os sambadores e sambadeiras nesse quadro político do Patrimônio. Mesmo a ASSEBA sendo fruto de um processo político de "fora", isso não significa uma passividade ou falta de agência desses grupos. Tal forma de organização é um dado novo inserido nessa realidade, mas seu uso permite também o empoderamento.

As pesquisas feitas para construção do Dossiê, partiram de alguns modelos prontos que pretendiam enquadrar a manifestação segundo parâmetros, dentre eles a demarcação espacial, de preferência uma pequena comunidade. $\mathrm{O}$ Recôncavo baiano do IPHAN, dessa forma, aparece de forma bem reduzida em relação às concepções da ASSEBA. O próprio nome da ASSEBA foi um dado conflitivo, como destaca Mestre Bule-Bule publicamente em uma reunião de mestres e mestras do Samba de Roda:

\footnotetext{
2 Como os sambas rurais em São Paulo, o Samba de Veio em Petrolina presente nas ilhas do São Francisco, o Samba de Coco em vários estados do Nordeste e tantos outros.

3 Organização das Nações Unidas para a Educação, a Ciência e a Cultura.

4 Através de uma reunião em que os sambadores e sambadeiras apresentaram suas principais demandas, o plano foi estruturado em quatro eixos: organização, transmissão, difusão e documentação.

5 Instituto do Patrimônio Histórico e Artístico Nacional.

6 Neste mesmo ano o Samba de Roda do Recôncavo Baiano recebeu também o título Patrimônio Oral da Humanidade pela UNESCO.
} 


\begin{abstract}
Antônio Cardoso, minha terra. É uma cidade que faz parte dessa ligação geográfica do Recôncavo da Bahia. É a ligação da Caatinga com o Sertão. E ali está um samba totalmente diferente de muitos outros sambas de roda da Bahia. Tinha uma pressa para fazer isso. Queriam fazer uma associação de Samba de Roda do Recôncavo. Gente? A Bahia toda samba! (Mestre Bule-Bule, 31 de outubro de 2015).
\end{abstract}

Mestre Bule-Bule, que foi o primeiro coordenador geral da ASSEBA, assinala também que a proposta inicial do nome, além de se limitar ao Recôncavo, só contemplaria os homens: "Associação dos Sambadores do Recôncavo Baiano". Mesmo tendo a figura de Dona Dalva como uma das principais proponentes para o pedido do título de patrimônio e toda a importância das sambadeiras na configuração dos sambas. Após muitas discussões, sambadores e sambadeiras, conseguiram determinar o nome como “Associação de Sambadores e Sambadeiras do Estado da Bahia”, contrariando os interesses políticos imediatos.

Os grupos de Conceição do Jacuípe, na medida em que fazem parte da ASSEBA, estão inseridos na política do patrimônio. Enquanto os grupos de Riachão do Jacuípe, cidade localizada no Sertão baiano, estão fora. O uso simultâneo da preposição-artigo "no/do" - em relação aos sambas no/do Sertão baiano - indica uma tentativa linguística de contraposição a uma vinculação meramente espacial e delimitada como proposta na política patrimonial. A sentença que prevalece tanto no Registro quanto no Dossiê é o "Samba de Roda do Recôncavo Baiano", já que torna a manifestação "espacialmente delimitável”, embora existam outras tradições de Sambas de roda no estado da Bahia, e a própria ideia de "Recôncavo baiano" a depender dos critérios abarca diferentes territórios.

Conceição do Jacuípe é um município do Estado da Bahia que se localiza a cerca de 97 quilômetros da capital baiana, Salvador, e a 28 quilômetros de Feira de Santana. Existem dois grupos de Samba de Roda em Conceição do Jacuípe7. O grupo Coisas de Berimbau é formado por sambadores e sambadeiras em sua maior parte já idosos, com faixa etária em média de 60 a 85 anos. O tipo de samba do grupo é o samba beira-mar, também chamado de santo amarense ou samba chula. E o grupo Raízes da Pindoba formado por cerca de oito a dez pessoas, não possuindo sambadeiras. O samba feito pelo grupo é chamado de samba corrido, que se caracteriza por uma dinâmica mais rápida.

O termo "beira-mar" indica a associação com o Recôncavo baiano, a região que está em volta da Baía de Todos os Santos, portanto "beirando" o mar. As chulas são miniaturas poéticas que relatam o cotidiano dos sambadores e sambadeiras. Um sambador (ou uma dupla de sambadores) canta os versos principais que são as chulas e são respondidos por outro sambador (ou uma dupla de sambadores) em coro com as sambadeiras, esta resposta é chamada de arremate ou relativo.

7 Para mais detalhes sobre os sambas em Conceição do Jacuípe, ver Bernardes (2016). 
Katharina Doring (2016), no seu livro Cantador de Chula: o samba antigo do Recôncavo baiano, sintetizando mais de 15 anos de pesquisa, fez um estudo dos sambas chulas em específico, porém indicando vários caminhos para uma abordagem crítica das musicalidades negras na Bahia. Interessante notar que o Recôncavo baiano como universo empírico de sua pesquisa não é aquele do discurso oficial, mas sim um espaço complexo, "de milhares de meandros e desdobramentos geo-culturais, socioeconômicos e valores espirituais". O trabalho da etnomusicóloga também se debruça nas histórias de vidas de diversos mestres e mestras. Por uma questão de recorte e de afinidades com os grupos, sua pesquisa está inserida no Recôncavo baiano, porém além da visão do mesmo, a autora cita outras tradições de sambas de roda no Semi-Árido baiano, por exemplo.

Assim, o samba beira-mar se caracteriza pelo canto e resposta; enquanto um sambador "grita" o samba (ou seja, o "puxador", aquele que conduz o repertório e decide quais músicas cantar), o outro sambador (e as sambadeiras também) "rela", responde o que o outro disse. É o chamado relativo que caracteriza as chulas. O grupo utiliza fardas, camisas com o nome do grupo, inclusive as sambadeiras. Os homens trajam camisas com a nomenclatura do grupo (de cores verde ou azul) e calças; os mestres usam chapéus. As mulheres, além das camisas mencionadas, usam saias rodadas coloridas. As vestimentas são muito próximas entre os grupos de Conceição do Jacuípe e Riachão do Jacuípe, na medida em que as camisas padronizadas com os respectivos nomes dos grupos são uma constante. O uso do chapéu entre os homens, bem como as saias entre as mulheres são outras características semelhantes.

Existem dois momentos fundamentais durante o samba que se alternam por toda a apresentação. Quando começa, o samba tem uma característica instrumental. Os músicos se posicionam em um semicírculo que é completado pelas sambadeiras. Quando o "puxador" inicia as chulas, o centro do círculo permanece intocado. Enquanto a letra é cantada, as sambadeiras continuam completando o círculo e cantando. Quando a letra é finalizada, o samba volta a ser instrumental. Nesse momento, as sambadeiras vão dançar dentro do círculo, primeiro saudando cada músico, com os passos característicos do chamado "miudinho", onde os pés quase não saem do chão e os seus corpos mais se parecem pêndulos em movimentos suaves. Em Riachão do Jacuípe, em contraposição ao "miudinho", o passo característico é a "pisada" em que tanto homens quanto mulheres dançam como se estivesse trotando em um cavalo, mudando constantemente de direção.

\section{Os Sambas no/do Sertão baiano}

A posição que adoto é pensar o Patrimônio Cultural a partir de grupos que estão fora desta política. Alguns grupos do Sertão baiano acabam ficando à margem de todo esse processo. Se por um lado há um desfavorecimento político 
em não receber o título patrimonial, bem como os recursos que advém deste processo, os grupos do Sertão baiano podem indicar a possibilidade de um novo entendimento do título. Sendo que o critério principal do IPHAN - em relação a este processo em específico - é se o samba confere uma identidade ao grupo, os sambas no/do Sertão baiano apresentam novas sociabilidades, instrumentos específicos, criatividades peculiares de disputas de versos e danças que se somam ao quadro geral de tradições dos sambas de roda no Estado da Bahia. Existe uma pluralidade de tradições de Sambas de roda na Bahia, com denominações de vertentes diferentes (samba beira-mar, samba corrido, samba barravento, samba de viola, samba boiadeiro, samba berrado, samba rojão, samba de enxada e tantos outros). Apresento especificamente o samba berrado na cidade de Riachão do Jacuípe, como uma tradição do samba fora da Política Patrimonial. O samba berrado integra, junto com outros estilos (como o samba boiadeiro e o rojão), os sambas no/do Sertão baiano.

Riachão do Jacuípe é uma pequena cidade do Sertão baiano, mas com uma extensa área territorial que abarca muitas comunidades rurais. Sua área territorial é de 1.190, $197 \mathrm{~km}^{2}$. A história dos sambas está ligada a fazendas antigas. Hoje estas fazendas são comunidades rurais que fazem parte do município de Riachão do Jacuípe. A região das Pedrinhas, localizada cerca de 10 $\mathrm{km}$ da zona urbana, é um dos espaços que tanto os sambadores quanto a população de forma geral atestam: "o samba começou nas Pedrinhas".

Dois grupos de samba estão ligados a esta região por questões históricas e familiares: o Sufoco da Fumaça, cuja principal liderança é José Cândido Carneiro e o grupo Chapéu de Couro (ou Samba das Pedrinhas), de Mizael Carneiro. Outras comunidades rurais da cidade possuem grupos de samba e demandam futuras pesquisas. Contudo, faço o recorte da região das Pedrinhas pela sua relação com Mizael e Zé Cândido, os principais interlocutores desta pesquisa.

Em Riachão do Jacuípe, meu contato inicial com os sambadores foi intermediado por Renilson Luis. Morador de Riachão desde o nascimento, funcionário da prefeitura, grande admirador dos sambas de roda da cidade e irmão da minha mãe. Conheci Zé Cândido e Mizael então em março de 2015. Ao primeiro contato, para eles, eu era apenas um jovem pesquisador curioso sobre os sambas da cidade. Nossas conversas ao longo da pesquisa passaram de um caráter formal para um "encontro etnográfico" de fato, além de encontros musicais. Isso foi facilitado pelas relações que foram sendo reveladas entre o samba e a minha família.

A questão da família é fundamental nos sambas de roda. Primeiro porque os sambadores e sambadeiras trazem esta musicalidade como uma "herança de família". Os atuais sambadores e sambadeiras da cidade são filhos e filhas (netos e netas) de sambadores e a sua inserção nos sambas foi através dos seus familiares. Segundo, é muito comum irmãos e primos fazerem parte de um mesmo grupo de samba. Isto não quer dizer que um grupo abarca apenas familiares. Um grupo é formado por pessoas aparentadas ou não, mas que 
possuem laços de amizade e afinidade, mesmo quando não são parentes. No grupo Chapéu de Couro, por exemplo, existem irmãos e primos. Porém existem outros sambadores que não são parentes de Mizael e seus irmãos, mas que também possuem uma "herança de família" ligada ao samba8.

A atividade escrita é sempre marcada por um distanciamento temporal e espacial entre antropólogos e interlocutores. A escrita, em certo sentido, é um processo tanto de reflexão quanto de memória. Dessa forma esse distanciamento espaço-temporal na escrita deve ser compensado por um compartilhamento do passado, visando uma integração no presente entre antropólogos e interlocutores (FABIAN, 2013).

Além das problemáticas do "escrever", outros elementos cognitivos são fundamentais nessas articulações entre texto e trabalho de campo: o "olhar" e o "ouvir". Que o "olhar" deve ser apreendido segundo um esquema conceitual antropológico que determina certa "visão de mundo" e, o "ouvir" como um complemento que busca estar entre as diferenças dos "idiomas culturais", numa perspectiva relativizante, já faz parte de um manual do trabalho do antropólogo (CARDOSO DE OLIVEIRA, 2006). Contudo, penso justamente na dimensão da aprendizagem de forma dialética: o antropólogo que observa e escuta buscando uma compreensão de uma dada estrutura simbólica; e o músico que observa e escuta para aprender as estruturas musicais. E mais além, a compreensão dos sambas de um lado por uma via antropológica (e por isso mesmo embasada em uma bibliografia específica do tema, bem como da própria literatura antropológica) e do outro lado pelo momento ritual de aprendizagemsocialização nos sambas.

O instrumento de corda (e o único cordofone) utilizado nos grupos pesquisados - Chapéu de Couro e Sufoco da Fumaça - é o cavaquinho. O cavaquinho embeleza a música e orienta a "altura" da melodia. Sem o cavaquinho para "orientar a altura" da melodia, as vozes ficam sem o "tempero na garganta". "Um cantava mais alto, outra cantava mais baixo. E o instrumento é pra isso, pra regularizar a música, a altura, embelezar”, segundo Zé Cândido. Como eu já tocava violão e tendo mais facilidade com cordofones do que com instrumentos percussivos, decidi tentar aprender cavaquinho com Seu Vardemar, tocador de cavaquinho do grupo Chapéu de Couro. Tocador é a categoria êmica utilizada para os sambadores que tocam algum instrumento.

No intuito de apresentar diversos elementos que compõem o samba berrado em Riachão do Jacuípe, as informações serão organizadas a partir de uma experiência musical com os sambadores. $\mathrm{O}$ fio condutor de análise parte de uma noite de samba que pude compartilhar momentos musicais com o grupo de Mizael. Porém outras informações serão agregadas à medida que os principais

8 Zé Cândido é meu primo de segundo grau, ou seja, ele é primo em primeiro grau da minha mãe porque meu avô materno é seu tio. O pai de Zé Cândido, chamado de Zezeca e também sambador, era irmão do meu avô. Francisca, mãe do meu avô (Antônio), por conseguinte mãe de Zezeca, era filha de Zuza das Pedrinhas (José João Carneiro), apontado como o sambador mais antigo da região, seu nascimento remete ao final do século XIX. Zuza das Pedrinhas então é meu tataravô. Os pais de Mizael também são primos de Zuza das Pedrinhas. Genealogia feita apenas para descrever as relações entre Mizael e Zé Cândido com a região das Pedrinhas e seus sambas e, de certa forma, suas relações de parentesco comigo. 
elementos forem apresentados. Como uma forma didática de apresentação de texto, será utilizado um momento específico em que o tocador-antropólogo teve a oportunidade de participar de um "treino" com o grupo, porém os dados representam a totalidade da pesquisa de campo empreendida.

Primeiro serão abordados os bastidores desta reunião. Segundo, serão apresentados e descritos os instrumentos utilizados no samba. Terceiro, me reporto à aprendizagem-socialização de Mizael e Zé Cândido nos sambas de roda, destacando sambadores antigos de Riachão do Jacuípe e as dimensões rurais dos sambas. Quarto é exposto um momento de aprendizagemsocialização a partir do cavaquinho. Quinto, além das coreografias, são destacados os elementos constitutivos do samba berrado como: os batuques, as chulas, as disputas de dança e de versos. Por fim abordo o Festival Regional de Samba de Roda em Riachão do Jacuípe. O samba de roda é um elemento central para a identidade destes grupos no Sertão baiano. Somando o quadro das tradições dos sambas de roda no Estado da Bahia, as "rodas" fora da Política Patrimonial trazem a possibilidade de refletir sobre outras sociabilidades: o "brincar" de samba indica outros caminhos de inventividade em suas dimensões de disputas de versos e danças. Fora deste discurso oficial do Patrimônio, os sambas no/do sertão indicam uma forma distinta de se saber-fazer samba.

Conversei com Mizael que estava interessado em aprender a tocar cavaquinho. Mizael então foi conversar com Seu Vardemar para saber sobre a sua disponibilidade para me ensinar. No caso dos sambas de roda a aprendizagem está ligada à socialização dentro do próprio ritual da musicalidade. Ou seja, aprende-se o samba "tocando e sambando" de fato. Neste ínterim, Mizael e Seu Vardemar decidiram marcar um "treino" (ensaio) na casa do irmão de Mizael, nas Pedrinhas. Era uma reunião de amigos de longa data, todos conversando, perturbando e rindo uns dos outros.

Fez-se uma roda na sala de estar. Os instrumentos utilizados eram: cavaquinho (o meu e o do Seu Vardemar, porém apenas um cavaquinho é utilizado nos sambas, exceto nesses momentos de aprendizagem-socialização), além da cuia e do pandeirog.

A cuia é "uma banda de uma cabaça”. É tocada com uma baqueta de madeira na sua parte de trás e o som é ressoado pela parte côncava aberta. Mizael é o tocador de cuia e seu instrumento tem uma particularidade, sua cuia não é feita da cabaça, mas de um material acrílico (o casco de um capacete de moto). Mizael diz que o som feito de cabaça é diferente da sua cuia "sintética", porém a sua "aguenta mais porrada". O pandeiro é responsável pelo "rojão" (ritmo) principal. Antigamente, no samba eram necessários dois ou três pandeiros. Enquanto um ou dois estavam sendo tocados, o outro ficava no fogo afinando. Eram feitos de couro de bode. O couro em contato com o fogo estica. Nos instrumentos de percussão de pele sintética essa afinação é feita esticando a pele com parafusos. Nos pandeiros feitos com couro de bode era o fogo a

9 "Instrumento popular brasileiro que tem em sua ascendência o 'Daff' árabe. Há indícios de que foi introduzido no acompanhamento dos gêneros ‘Samba' e ‘Choro' no início do século XX” (REPPOLHO, 2012: 75). 
ferramenta de afinação. Outros instrumentos podem ser utilizados no samba: uma enxada bem pequena sem o cabo de madeira, tocada com uma baqueta de ferro (ou o próprio cabo da enxada).

Então, no quadro percussivo estão o pandeiro, a cuia e a enxada. Outro elemento também fundamental para o "rojão" do samba são as palmas. Assim a palma teria uma função de instrumento, na medida em que ajuda a preencher o ritmo.

As palmas também fazem parte de um momento no samba fundamental: "o parmeado". Além dos sambadores que batem as palmas seguindo o "rojão" principal do samba, no "parmeado" alguns "cortam as palmas", ou seja, batem palmas no contratempo. É um momento essencialmente instrumental e pode ser "puxado" pelo cavaquinho ou pela cuia. Normalmente os mesmos sambadores que cantam, também fazem o "parmeado". Assim, três ritmos diferentes de palmas se entrecruzam em contratempos, e os tocadores, quando são bons - no pandeiro, na cuia ou no cavaquinho - reproduzem nos instrumentos o "rojão" do "parmeado". As sambadeiras respondem balançando os quadris e pisando mais rápido no chão. No mínimo o "parmeado" exige três sambadores para bater palmas. Normalmente os grupos possuem cerca de dez integrantes que se distribuem entre os tocadores e os sambadores que puxam os sambas cantando e batendo palmas, fora as sambadeiras. No caso dos "treinos" as pessoas envolvidas se resumem aos integrantes dos grupos. Na ausência de sambadores para bater as palmas ou mesmo para o descanso dos mesmos, existe um instrumento que simula as palmas: a pachola (e seu tocador chama-se pacholeiro).

A pachola é feita com dois ou três pedaços de madeira cerrados em retângulos e presas com um arame. A cuia e a pachola são os dois instrumentos peculiares destes sambas no/do Sertão baiano. Em minhas pesquisas e na literatura sobre o samba de roda, sobretudo no Recôncavo baiano, não há registro destes instrumentos. O caso da pachola é ainda mais curioso. Não encontrei registros deste objeto enquanto instrumento. Nos sambas no/do sertão, como a palma também é um instrumento, este objeto, denominado pelos sambadores de pachola, adquire também uma conotação instrumental.

Fechando este parêntese sobre os instrumentos, os sambam revelam também sua faceta para grandes brincadeiras. Uma dessas dimensões seria o "Reis Roubado":

Roubava o "Reis". Cantava o "Reis". O pessoal tava dormindo. Aí juntava a turma toda. Foguete. Uma zuada danada. Aí o cara acordava com a zuada e samba até de manhã. Mas naquele tempo era bom. Samba de roda na varanda e brinquedo de roda na sala. Era uma disputa. (Mizael, 22 de março 2015).

O samba é sempre visto como uma brincadeira. Fazer samba é intrinsecamente brincar de samba. O próprio "Reis Roubado" ou "Samba Roubado" é uma grande brincadeira. Desde quando se começa a pensar que casa será "roubada" (ou seja, a casa que os sambadores e sambadeiras levarão o samba de surpresa), até mesmo àqueles que não se deixam ser surpreendidos. 
Maria Candeal, sambadeira do Grupo Ramos1o - mas que já sambou com Mizael e Zé Cândido - enfatiza que nunca foi surpreendida. Pela movimentação e pergunta de pessoas próximas, ela sempre desconfiava e, quando o samba chegava, ela já estava preparada para receber os sambadores e sambadeiras com comidas e bebidas. No "Reis Roubado", o grupo de samba com outras pessoas que também participarão do evento (prestigiando, dançando, comendo, bebendo) organizam tudo. Chegam de surpresa na casa em que ocorrerá o samba com todos os "comes e bebes".

Os sambas em Riachão aconteciam nas fazendas. Mizael e Zé Cândido, ainda crianças aprenderam a "bater" cuia acompanhando seus pais nos sambas. Ambos conheceram e sambaram com uma figura importante do samba da região: Isidio das Pedrinhas, filho de Zuza das Pedrinhas. Isidio Miguel Carneiro nasceu nas Pedrinhas em 1925 e foi um famoso sambador, conhecido como o "Rei do Samba", chegou a gravar um programa de televisão em Salvador com o seu grupo de samba. Batia pandeiro, cuia e cantava não só samba, como outros estilos também.

O samba ligado à dimensão rural apresenta uma cooperação de trabalho entre a comunidade com o chamado "Batalhão".

\footnotetext{
Alguém tinha uma roça de milho. Vinte, trinta "leva" de milho. E eu digo: vou roubar ele. Roubar é juntar o pessoal todo e pegar ele sem saber que a gente ia lá. Soltava foguete, fazia aquela zuada e capinava o milho todinho naquele dia. Aí sambava à noite. Eu tenho um tio que sambou três noites e três dias sem parar. Totonho das Pedrinhas. (Mizael, 22 de março 2015).
}

Ao terminar o "batalhão", que era o trabalho na agricultura, saindo da roça para entrar na casa se cantava a "bandeira". As mulheres ficavam em casa com uma bandeira branca e os homens chegavam da roça com uma bandeira vermelha. Cantavam então um batuque da bandeira11.O "batalhão" e os batuques de bandeira evocam assim a dimensão rural desses sambas. Embora com menos frequência do que o "Reis roubado" nas comunidades rurais continuam tais tradições.

Na casa do irmão de Mizael a roda então se fez na sala. A afinação do meu cavaquinho era a "padrão" (Ré Si Sol Ré). Ao ouvir as cordas soltas, Seu Vardemar já atentou que deveria se baixar a afinação, porque estava muito "alta" (aguda). Perguntei então quais eram as notas para as cordas soltas. Ele me respondeu tocando a primeira corda do instrumento: "essa!". Fui percebendo que a relação com o instrumento está no ouvir e não nas nomenclaturas. Afinei então o meu cavaquinho segundo a afinação que estava no dele e eram as seguintes notas: Si, Sol sustenido, Mi, Mi (uma oitava abaixo). A relação é da corda mais aguda para a mais grave, ou verticalmente das cordas dispostas de baixo para cima. Outros sambadores e Seu Vardemar então perceberam que o cavaquinho ainda estava muito agudo e outra afinação foi

10 O grupo Ramos foi fundado por "Raminho", primo de Zé Cândido e tocador de cavaquinho.

11 Toda cheia de valor// Quem enfeitou essa bandeira// Foi uma moça de amor// Ô bandeira vermelha// Muito louvador. Versos transmitidos por Everaldo, filho Manezinho de Isaías. 
posta: Dó, Lá, Fá, Fá (uma oitava abaixo), descendo meio-tom. O nome dessa afinação é "travessa".

Existem diversas tradições de sambas no/do Sertão baiano como o samba boiadeiro e o samba berrado. O samba boiadeiro é mais lento, com histórias longas e sem a presença de sambadeiras. A tradição do samba em Riachão do Jacuípe é o samba berrado. Este samba tem uma cadência rápida (mais rápida que o samba corrido do Recôncavo baiano). Alguns momentos na roda são definidos. Nas chulas apenas os homens cantam em duplas (primeira e segunda vozes). As chulas são versos poéticos que tratam sobre a vida dos sambadores, contam histórias vividas e ouvidas por seus compositores. Mesmo com a presença das chulas, o samba de Riachão do Jacuípe é denominado samba berrado. $\mathrm{O}$ samba chula ou beira-mar é assim chamado em algumas regiões do Recôncavo baiano. O "berrado" remete justamente aos cantos e respostas, a complementaridade entre aqueles que cantam e aqueles que respondem, o chamado canto responsorial.

Nos batuques os homens cantam e as mulheres respondem (terceira voz). Os batuques também são versos, mas com uma estrutura fixa que sempre se repete. Nesse momento, as mulheres podem sambar sozinhas ou em duplas; na chula, samba apenas uma de cada vez. A roda é composta por sambadores e sambadeiras. Nos batuques, enquanto algumas sambadeiras estão cantando, outras (sozinhas ou em duplas) deslocam-se para o centro da roda, saudando os tocadores. Nas chulas, as sambadeiras fazem esse mesmo percurso sozinhas. Saem tangenciando a roda formada em direção ao centro, depois retornam para compor a roda novamente. As sambadeiras vestem saias grandes e uma camisa padronizada do grupo. Sambam normalmente descalças ou com sandálias baixas. O movimento segue muito o ritmo da cuia, como se tivesse trotando, pisando forte no chão, ao mesmo tempo que requebra os quadris, com os braços em movimento ou para baixo. Durante o "parmeado" o requebrado dos quadris é acentuado.

O samba berrado de Riachão do Jacuípe apresenta também duas dimensões de disputa: uma na dança e outra nos versos. A disputa na dança é chamada de "piegas". Dançar a "piegas" consiste numa disputa entre homens para decidir qual é o sambador mais inventivo nas coreografias. A dança difere da coreografia "feminina" do samba, apesar de alguns elementos como a "pisada" no chão como se estivesse trotando em um cavalo é uma característica comum para homens e mulheres. Os homens usam chapéus e calça e sambam usando botas de couro. Não requebram os quadris, dançam como se tivessem marchando em um cavalo, mudando constantemente a direção.

A disputa nos versos é chamada de "martelo" ou "batuque de quadra". A concepção do martelo, enquanto uma disputa de versos, consiste em o sambador ficar "martelando" (pensando, memorizando e improvisando) versos para fazer o outro sambador "cair". 
Dionísio no Poço Danta// Vadeia porque conhece// Puxa a guela da garganta// Quem dança não sapateia// Da garganta puxa a guela// Fazendo boca de riso// Quem sapateia não dança// No Poço Danta é Dionísio 12.

Um sambador de Riachão chamado Antônio de Zefa foi para Poços Dantas (uma fazenda antiga que fazia parte da cidade, hoje pertence ao município de Serrinha) e lá desafiou para o martelo Dionísio. Dionísio perdeu a brincadeira dos versos. Dez anos depois, Dionísio foi para Riachão buscar sua "vingança". Porém, Antônio de Zefa não sambava mais. Mané de Isaías então brincou no seu lugar e mais uma vez Dionísio "caiu” depois de horas de brincadeiras. Manoel dos Santos Silva, ou Manezinho de Isaías, junto com Isidio das Pedrinhas, são os dois nomes referências do samba de roda em Riachão do Jacuípe.

Outro traço fundamental dos sambas de roda em Riachão do Jacuípe é a existência do Festival Regional de Samba de Roda que acontece todos os anos no mês de novembro, uma inciativa de Zé Cândido. O Festival, sem contar com apoio da prefeitura, da ASSEBA ou qualquer política patrimonial já é uma tradição importante e esperada na cidade. Além dos grupos de Riachão do Jacuípe, que revezam participação durante os anos, o festival também abarca grupos de outras cidades do Sertão baiano e até de outras regiões, como a Chapada Diamantina.

\section{Política Patrimonial e a Interpelação dos sujeitos}

Não busco dicotomizar os sambas na Bahia entre Recôncavo e Sertão, muito menos essencializar tais espaços. Penso aqui no contexto de relações entre os grupos que se movimentam em seu território, que referendam determinadas tradições em função dos espaços. Contudo, essas nomenclaturas só são acionadas em situações específicas. O estilo samba berrado só é acionado enquanto discurso principalmente a partir do contato com grupos de estilos diferentes. Seus próprios nomes remetem aos espaços em que estão inseridos: Samba das Pedrinhas, Coisas de Berimbau, Raízes da Pindoba, só para ficar nos grupos em foco nesta pesquisa. Contudo, estes exemplos podem ser generalizados à maior parte dos grupos de samba de roda do território baiano.

Apesar de afirmar a existência do samba de roda em todo o Estado da Bahia, o texto contido no Dossiê do IPHAN busca justificar o "Recôncavo" como recorte espacial para legitimar a patrimonialização do bem cultural. Entretanto, como aponta Gupta e Ferguson "tanto o naturalismo etnológico como o nacional apresentam as associações de povo e lugar como sólidos, criteriosos e pacíficos, quando são, na verdade, contestadas, incertas e fluidas" (GUPTA; FERGUSON 1992, p. 38). Demonstrando também as caracterizações nativas sobre o Recôncavo e o Sertão baianos, o entendimento geral sobre esses espaços mostra-se mais diversos do que as imputações e delimitações feitas pelo Estado.

12 Versos transmitidos por Everaldo, filho de Manezinho de Isaías 
Ao longo do ano de 2015 foram realizadas “Assembleias itinerantes” em vários municípios contemplados pela ASSEBA, dentre eles Conceição do Jacuípe. A sistematização dos relatos gerou um documento enviado ao IPHAN intitulado Relatório das Assembleias de Articulação Itinerantes do Samba de Roda do Recôncavo Baiano. O relatório consiste em propor novos encaminhamentos para a Salvaguarda. Além de demandas diversas13uma das propostas principais é a modificação do título patrimonial, buscando a proposição do registro do Samba de Roda no território baiano.

Destarte, tanto a ASSEBA, ampliando esse entendimento inicial de Recôncavo contido no Dossiê (ou seja, mostrando justamente que essas representações espaciais são contestadas e fluídas), quanto as pesquisas sobre os Sambas de Roda permitem pensar nessas relações entre espaço, política e a própria representação antropológica.

O Samba de Roda tem sido objeto de estudo dentro da academia, sobretudo a partir de uma perspectiva etnomusicológica. Trabalhos como de Ralph Waddey (1980, 1981), Thiago de Oliveira Pinto (1991), Katharina Doring (2002), Francisca Marques (2003), Cassio Nobre (2008), Raiana Alves (2009) entre outros, fazem uma importante abordagem sobre esta musicalidade. Tais pesquisas trazem contribuições significativas de levantamento histórico e diferentes práticas etnográficas, versando sobre as memórias de sambadores e sambadeiras, bem como aspectos estruturais e particulares dos sambas de roda. O Dossiê Samba de Roda do Recôncavo Baiano, também foi organizado por um etnomusicólogo, Carlos Sandroni (2007). Alencar (2010) analisa a patrimonialização enquanto um ritual, estabelecendo conexões entre o Estado e os sambadores. Tais contribuições são importantes para atestar a pluralidade de tradições que envolvem os Sambas de Roda no estado da Bahia.

Por outro lado, a evocação da diversidade cultural, atrelada à Política Patrimonial, remete a uma noção liberal de multiculturalismo. Este discurso oficial busca então uma "fixidez" na construção da alteridade. Dessa forma, Bhabha coloca que "é somente pela compreensão da ambivalência e do antagonismo do desejo do Outro que podemos evitar a adoção cada vez mais fácil da noção de um Outro homogeneizado, para uma política celebratória, oposicional, das margens ou minorias" (BHABHA, 2013, p. 96).

O discurso da "diferença cultural", perspectiva adotada neste trabalho, se coaduna enquanto uma expressão das margens, engendradas em sociabilidades específicas e inventividades de sambas de rodas diferentes daquele patrimonializado, indicando a possibilidade de um novo entendimento sobre o título patrimonial, já assinalado também pela ASSEBA. Em contrapartida o discurso da "diversidade cultural” está preocupado de um modo uniformizador

13 Aumento da parceria entre universidades e a ASSEBA, capacitação de filhos(as) e netos(as) em metologias de pesquisa para o protagonismo da base social dos sambadores e sambadeiras, ações de maior valorização e visibilidade dos grupos, garantia da presença de mestres e mestras no ensino municipal e estadual, tendo como subsídio a lei $\mathrm{N}^{\mathrm{o}}$ 10.639, capacitação para elaboração de projetos, entre outras - o cadastramento de novos grupos, bem como um novo censo sobre os sambadores e sambadeiras do estado da Bahia. 
com comunidades e minorias, aproximando-se dos discursos de brasilidade, no plano da ideologia.

Dessa forma, a aceitação das políticas patrimoniais não implica numa passividade destes grupos. O conceito de cidadania patrimonial, elucidado por Lima Filho (2015) nas suas dimensões entre a adesão e a resistência, indica outras possibilidades de interação dos grupos e o Estado. A cidadania patrimonial deve ser pensada a partir dos grupos sociais e étnicos que a vivenciam. No caso do Samba de Roda do Recôncavo baiano, ela só se efetiva quando o grupo passa a fazer parte da ASSEBA. É nesse momento que a dimensão da política institucional começa a fazer parte da vida dos sambadores e sambadeiras.

O mito do Patrimônio descrito por Lima Filho (2015) como legitimador do discurso da cultura nacional é entendido aqui em seu aspecto ideológico, em sua positividade harmônica de uma realidade sem fraturas, como diria Zizek (1996). Ou seja, a Política Patrimonial é seletiva e consequentemente excludente, e se esconde atrás de uma retórica de constante salvaguarda e valorização dos bens representativos da identidade nacional, porém:

\begin{abstract}
qual seria o lugar do subalterno na representação do patrimônio brasileiro, aquele que não se encaixa na excepcionalidade ou na relevância/representatividade do patrimônio? O reverso do patrimônio tem lugar na cidadania patrimonial, potencializando a cidadania insurgente. Essa última possibilidade não tem sido contemplada pelos autores quando escrevem sobre o patrimônio. Ora, a análise do patrimônio distanciada do mito da nação só é capaz se consideramos o conflito ou a insurgência colada também ao conceito de cidadania. Dessa forma, a ação patrimonial movida pelos atores sociais desenha uma escala cuja mensuração vai do mito da nação à sua resistência/negação assumida por atores sociais que politicamente se situam nas margens, nas fraturas e clivagens, ou seja, em direção a uma ideia de anti-mito da nação. (LIMA FILHO, 2015: 140)
\end{abstract}

Identifico o reverso do patrimônio a partir dos Sambas no/do Sertão baiano, que potencializam a "cidadania insurgente" da ASSEBA na construção de estratégias de interação com a Política Patrimonial. Esse jogo de poder com o Estado é notadamente assimétrico. Nessa insubordinação, a ASSEBA subverte a tônica desta política e faz do título patrimonial um recurso de sobrevivência humana, em um contexto social desigual e historicamente explorado como a região do Recôncavo baiano. É nesse aspecto que consiste a noção de modulação alinhada ao conceito de cidadania patrimonial (LIMA FILHO, 2015). O contexto histórico escravista da região, o racismo derivado desse processo, as condições materiais de existência, todos esses elementos são acionados neste jogo político com o Estado. A ASSEBA se coloca institucionalmente nas suas ações como um agente de combate ao racismo e à intolerância religiosa aos cultos afrobrasileiros. Outro exemplo de modulação seriam as pautas constantes nas assembleias e diálogos com o IPHAN sobre a saúde dos mestres e mestras, bem como na própria possibilidade de se viver a partir do samba. Nas dimensões burocráticas de articulações e lideranças de grupos, promovendo oficinas e organizando eventos. E, também, na atividade remunerada para os sambadores e sambadeiras. 
A ASSEBA então configura a própria instância legal através da qual os trâmites e diálogos são realizados com o Estado. Mesmo tendo uma sede principal, existem Casas do Samba em muitos municípios que, de certa forma, descentralizam as decisões. Reuniões são sempre realizadas nestas Casas, com posteriores Assembleias Gerais organizadas na sede principal, contando com a participação de muitos sambadores e sambadeiras. Essa dimensão burocrática, presente no dia a dia dos grupos pertencentes à ASSEBA, indica a introjeção desta cidadania patrimonial. As ações da associação e seus grupos demonstram a operacionalidade desta cidadania, através da qual, podem até questionar sua própria titulação enquanto Patrimônio Cultural.

Para os grupos de Riachão do Jacuípe a temática do Patrimônio Cultural é uma realidade distante ou inexistente. Desconhecem a ASSEBA e todo o processo político da patrimonialização. Certa vez Mizael Carneiro, do grupo fora da Política Patrimonial, viu em um jornal televisivo que o Samba de Roda teria "virado" Patrimônio Cultural Brasileiro e achou positivo tal reconhecimento, já que o mesmo faz parte da história da cidade e da sua própria vida. A noção de patrimônio é percebida no seu valor de reconhecimento, um atestado "oficial" de importância para algo que para eles sempre foi importante, se me permitem a redundância.

Os grupos que pertencem à ASSEBA, mesmo aqueles recentes ou não assíduos nas reuniões e assembleias, identificam uma mudança no cenário do samba após o ano de 2004. Mesmo sem atrelar ao título de Patrimônio, conferindo uma importância maior à constituição da ASSEBA, a visão desses grupos é a de que "está se falando mais sobre o samba de roda nas cidades". Com o fortalecimento da Rede do Samba14 em vários municípios da Bahia, mais do que o título, a ASSEBA passou a desempenhar um protagonismo neste novo momento político para os grupos de sambas de roda.

Para a ASSEBA o reconhecimento patrimonial, além do processo de salvaguarda e todo o empreendimento de formação de novos grupos e ampliação dos associados no Estado da Bahia, é acompanhado de uma conscientização de que o Samba de Roda agora “também é política”. Se em seu estatuto se coloca como protetora do "patrimônio imaterial", nas suas ações políticas e trâmites com o Estado insinuam novas diretrizes para a Política Cultural, utilizando as ferramentas estatais como instrumentos de empoderamento. Contudo, a noção de Patrimônio Cultural entre seus grupos podem ser bem diversas, dada a heterogeneidade da sua formação.

Para os grupos envolvidos no processo de patrimonialização - os que foram proponentes do Registro e os diretamente pesquisados para o Dossiê desde o início o título significava um conjunto de ações concretas de valorização pelo Estado dos saberes e práticas vivenciados por eles e seus antepassados. Para grupos que começaram a fazer parte da ASSEBA após os anos de 2004 e

14 Articulação política das Casas de Sambas distribuídas em 15 municípios: Santo Amaro, Feira de Santana, Maragojipe, Antônio Cardoso, Saubara, São Francisco do Conde, São Felix, São Sebastião do Passé, Teodoro Sampaio, Conceição do Jacuípe, Cachoeira, Terra Nova, Irará, Salvador e Simões Filho. 
2005, o principal indicativo era a existência de uma associação que congregava grupos de sambas de roda e, não necessariamente, fazer parte do Patrimônio Cultural do Brasil. A medida que os grupos vão participando das reuniões e assembleias, a dimensão política começa a aparecer. O significado de fazer parte de algo que é Patrimônio Cultural é construído discursivamente nessas assembleias, nas quais os coordenadores e articuladores fazem a ponte entre $o$ Estado e sambadores e sambadeiras.

Por outro lado, dentro da própria ASSEBA existem grupos fora do "Recôncavo baiano" que não se sentem contemplados pelo título patrimonial. Comumente a retórica utilizada é a de que "a Bahia toda samba". Restringir esta importância a um local circunscrito, no âmbito dos discursos políticos, é desvalorizar outros grupos.

A Política Patrimonial revela sua missão social e seu compromisso com a construção do Patrimônio Cultural Brasileiro, o que implica refletir sobre os seus usos (SMITH, 2006). O samba patrimonializado, mais do que um indicativo local entre pessoas e um bem cultural, configura-se como um elemento de identidade nacional. No caso aqui específico, o Samba de Roda do Recôncavo baiano é também um bem simbólico que representa o Brasil no quadro planetário do discurso da "diversidade cultural".

O dilema da representatividade, indicado por Arantes (2009), envolve o poder de legitimação do Estado em conferir valor patrimonial a bens culturais. Por outro lado, as políticas do Patrimônio Intangível, que abarcam manifestações afro-brasileiras e indígenas, segundo o mesmo autor, tendem a regular o equilíbrio das políticas de patrimônio no Brasil, historicamente marcada por priorizar referências brancas, católicas e coloniais. Como demonstrado no jogo político da cidadania patrimonial, as margens que se anunciam, o "reverso do patrimônio", não só indicam as contradições da ordem hegemônica, como demonstram posturas insurgentes nas relações com o Estado.

A Política Patrimonial interpela os diversos sujeitos de diferentes formas. Para o cidadão comum fora do contexto dos sambas, nas cidades de Riachão do Jacuípe e Conceição do Jacuípe, o Patrimônio Cultural remete muito mais à concepção de Tombamento do que de Registro. Ou seja, a percepção patrimonial se conecta mais a monumentos, cidades históricas, aos bens de "pedra e cal" (FONSECA, 2001).

Para os sujeitos de bens patrimonializados o título patrimonial opera em um processo de somatória e não de substituição. Antes deste processo, os sambas na Bahia possuíam (e ainda possuem) diversas conotações. Uma herança dos antepassados africanos, uma resistência diante do poder colonial, divertimento e brincadeira, um sentido religioso como parte integrante de rezas e pagamentos de promessas, um elemento facilitador para o trabalho rural ao promover mutirões que ajudam nas colheitas, como um elemento do calendário festivo das cidades e tantas outras. A estes múltiplos sentidos é somada a noção de que também é um Patrimônio Cultural do Brasil. Cabe à ASSEBA difundir e 
apresentar esta nova faceta aos sambadores e sambadeiras que, ao participarem das reuniões, aos poucos, assimilam este discurso patrimonial.

Assim a permanência de múltiplos referenciais para sambadores e sambadeiras é também indicativo de resistência aos discursos uniformizantes e rígidos da Política Patrimonial. Os próprios Sambas no/do Sertão baiano retroalimentam a "cidadania insurgente" da ASSEBA. Na interpelação dos sujeitos pela política cultural, não há uma constituição de sujeitos do patrimônio e, sim, de sujeitos de bens patrimonializados. Na medida em que a Salvaguarda é subvertida não só para a valorização do bem cultural, mas sobretudo, para o empoderamento destes sujeitos, o campo patrimonial tem sido um palco de disputas e renegociações entre o Estado e os grupos.

\section{Considerações Finais}

As "rodas" realizadas fora da Política Patrimonial aparecem como um local importante para se pensar as contradições da patrimonialização de um bem cultural. Os Sambas no/do Sertão baiano possuem, em alguma medida, interações com o Estado, mas não sob a égide da política patrimonial. A coexistência das dinâmicas musicais citadinas e rurais - em Riachão do Jacuípe, com suas chulas, batuques, martelos e piegas - denotam as diferentes feições que os sambas de roda podem adquirir. Seja na sua dimensão de musicalidade atrelada à labuta diária no campo, embalando as rezas e divertindo a todos com sua faceta de brincadeiras ou em grandes festivais, como parte integrante do calendário festivo da cidade.

A distorção, ao não enfatizar a pluralidade de tradições dos sambas em todo o estado da Bahia, é um dos elementos da Política Patrimonial que é criticada pelas práticas da ASSEBA. Como já visto, seu próprio nome remete a uma associação que visa ocupar um espaço maior do que aquele ao qual a política pública designou. Ao agregar cada vez mais associados de diferentes regiões da Bahia, visa também a modificação de um título que é restritivo. Mais do que isso, conseguir a mudança do título significa reinscrever pelas margens o discurso patrimonial, mais atento às demandas e vozes dos portadores dos bens, do que dos parâmetros e critérios de instituições do Estado. Contudo, integrarse também é fazer parte no jogo da ideologia da identidade nacional.

Todos esses elementos podem ser elucidativos para repensar outras qualificações desse valor patrimonial, que podem ser mais problematizadoras e flexíveis em relação ao poder do Estado sob a regulação da cultura. 


\section{Bibliografia}

ALENCAR, Rívia R. B. O Samba de Roda na Gira do Patrimônio. Tese (Doutorado). Departamento de Antropologia Social, UNICAMP, 2010.

ALVES, Raiana. A política de salvaguarda do patrimônio imaterial e os seus impactos no samba de roda do recôncavo baiano. Dissertação (Mestrado). Departamento de Etnomusicologia, UFBA, 2009.

ARANTES, Augusto A. Sobre inventários e outros instrumentos de salvaguarda do patrimônio cultural intangível: ensaio de antropologia pública. In: Anuário Antropológico 2007/2008. Rio de Janeiro, Tempo Brasileiro, 2009. p. 173-222.

BERNARDES, Marcus. A Construção Social da Música: Patrimônio Cultural e Samba de Roda em Conceição do Jacuípe. In: BENEVIDES, S. C. O., PENTEADO JUNIOR, W. R. (org.). Pelas Lentes do Recôncavo: escritos de teoria social, artes e humanidades. Cruz das Almas: Editora UFRB, 2016, p. 4967.

BHABHA, Homi. O Local da Cultura. Belo Horizonte: Editora UFMG, 2013.

CARDOSO DE OLIVEIRA, Roberto. O Trabalho do Antropólogo. Brasília, Paralelo 15; São Paulo, Unesp, 2006.

DORING, Katharina. O samba de roda do Sembagota: Tradição e contemporaneidade. Dissertação (Mestrado). Departamento de Etnomusicologia, UFBA, 2002.

baiano. Salvador: Pinaúna, 2016.

Cantador de Chula: o samba antigo do Recôncavo

FABIAN, Johannes. O Tempo e o Outro: como a antropologia estabelece o seu objeto. Petrópolis, Vozes, 2013.

FONSECA, Maria Cecília L. Para além da pedra e cal. Rio de Janeiro: Revista Tempo Brasileiro, v.1, n. 147, 2001.

GUPTA, Akhil; FERGUSON, James. Beyond Culture: Space, Identity and the Politcs of Difference. Cultural Anthropology. n. 1, vol. 7, pp. 06-23, 1992.

IPHAN. Samba de Roda do Recôncavo Baiano. Brasília, Dossiê IPHAN 4, Ministério da Cultura, 2007.

LIMA FILHO, Manuel Ferreira. Cidadania Patrimonial. Revista Anthopológicas. Pernambuco, ano 19, 26 (2), 2015, p. 134-155.

MARQUES, Francisca. Samba de roda em Cachoeira, Bahia: Uma abordagem etnomusicológica. Dissertação (Mestrado). Departamento de Etnomusicologia, UFRJ, 2003. 
NOBRE, Cassio. Violas nos sambas do Recôncavo Baiano. Dissertação de mestrado, UFBA, 2008.

OLIVEIRA PINTO, Tiago. Capoeira, Samba, Candomblé. Afro-brasilianische Musik im Recôncavo, Bahia. Berlim: Staatliche Museen / Preussischer Kulturbesitz, 1991.

REPPOLHO, Givaldo José dos Santos. Dicionário Ilustrado de Ritmos e Instrumentos de Percussão. Rio de Janeiro, GJS Editora, 2012.

SANDRONI, Carlos. Samba de Roda, patrimônio imaterial da humanidade. Estudos Avançados. São Paulo, vol. 24, n. 69, 2010.

SMITH, Laurajane. Uses of Heritage. London / New York: Routledge Taylor \& Francis Group, 2006.

WADDEY, Ralph Cole. 'Viola de Samba' and 'Samba de Viola' in the Recôncavo of Bahia (Brazil). Latin American Music Review, vol. 1, n. 2, pp. 196- 212, 1980.

. 'Viola de Samba' and 'Samba de Viola' in the Recôncavo of Bahia (Brazil) Part II: 'Samba de Viola'. Latin American Music Review, vol. 2, n. 2, pp. 252-279, 1981.

ZIZEK, Slavoj. O Espectro da Ideologia. In: ZIZEK, Slavoj (org.). Um mapa da Ideologia. Rio de Janeiro: Contraponto, 1996. P 07-38.

Recebido em 25/04/2017. Aprovado em 12/09/2017. 